\title{
Is Limb Loss Always Inevitable for Critical Neuro-Ischemic Foot Wounds in Diabetic Patients with End Stage Renal Disease and Unfit for Vascular Reconstructions?
}

\author{
Vlad Alexandrescu \\ Department of Thoracic and Vascular Surgery \\ Princess Paola Hospital \\ Marche-en-Famenne \\ Belgium
}

\section{Introduction}

End stage renal disease (ESRD) and diabetes mellitus are independently associated with advanced atherosclerosis with extended arterial wall calcifications and occlusions in inferior limb arteries (Norgreen et al., 2007). A severe arterial affectation was commonly documented in critical inferior limb ischemic (CLI) wounds, particularly located in the tibial trunks of these patients (Casserly, 2008; Norgreen et al., 2007). The association of CLI in subjects with impaired renal function and particularly ESRD leads to a notable higher rate of subsequent morbidity and mortality (Andreoli et al., 2008; Casserly, 2008; Mlekusch et al., 2004). Although revascularization indisputably represents the primary therapy for limb salvage (Casserly, 2008; Conrad et al., 2009; Norgreen et al., 2007), renal patients seem to require strikingly more challenging interventions, that focus hostile and diffusely diseased leg segments (Andreoli et al., 2008; Casserly, 2008; Conrad et al., 2009; Randon et al., 2010). Literature on arterial reconstruction (surgical and endovascular) reveals poor patency, tissue recovery and limb preservation data, coupled to high short and mid-term mortality rates for ESRD subjects (independently from other cardio-vascular risk factors) (Abou-Zamzam et al., 2007; Bradbury et al., 2010; Casserly, 2008; Leers et al., 1998). Similar observations were independently documented in diabetic ischemic limbs that have the metabolic and neuropathic background, local sepsis and important amount of tissue loss (Apelqvist et al., 1993; Dormandy et al., 1999; Edmonds, 2008; Norgreen et al., 2007). However, despite progresses in both surgical and endovascular approaches, in $14 \%-20 \%$ of these patients exhibiting advanced crural and pedal occlusive disease, neither of the available procedures can provide appropriate distal arterial supply, turning to amputation (Abou-Zamzam et al., 2007; Dormandy et al., 1999; Faglia et al., 2007). In these desperate cases, since all "conventional" arterial revascularization techniques were unsuccessful, the concept of "venous arterialization", as extreme alternative for delivering the oxygenated blood to distal ischemic tissues was considered. These limb salvage alternatives for extreme CLI presentations (currently intended to amputation) were mostly described as using the available superficial veins of the affected limb (Jacop et al., 1999; Lengua et al., 2001). 
While some reports claim encouraging limb salvage results (Jacop et al., 1999; Lengua et al., 2001; Lu et al., 2006), others remain reserved (Matzke et al., 1999).

Parallel efforts in CLI limb preservation were reported in the plastic reconstructive surgery field, by promoting the angiosomes model (AM) for reperfusion and tissue reconstruction upon specific arterial and venous bundles of blood supply (Attinger et al., 2001, 2006; Taylor \& Pan, 1998).

A schematic description of these tissue irrigation areas in the foot is illustrated in Fig. 1.

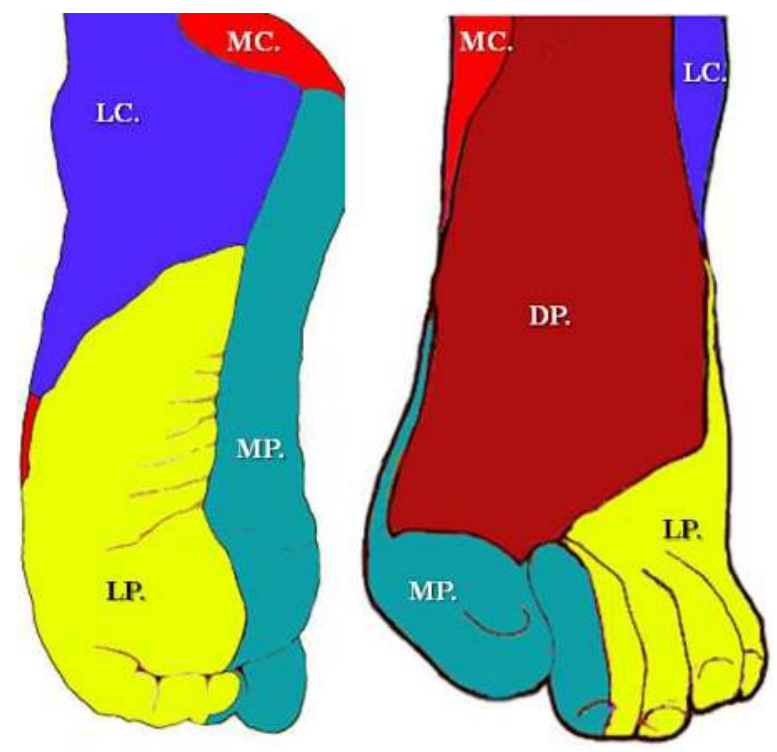

Fig. 1. A simplified illustration of the main angiosomes (and correspondent venosomes) related territories of the foot and ankle:

MC: The Medial Calcaneal Artery,

MP: The Medial Plantar Artery and LP: The Lateral Plantar Artery angiosomes, dependent from the Posterior Tibial Artery territory,

DP: The Dorsalis Ppedis Artery angiosome, from the Anterior Tibial arterial and venous bundle, and LC: The Lateral Calcaneal Artery angiosome from the Peroneal arterio-venous tract.

We propose to examine in this chapter the clinical efficacy of a new hybrid limb salvage technique (surgical and endovascular) for deep venous selective arterializations in extreme diabetic CLI presentations, unfit for any of the common arterial reconstructive methods (Alexandrescu et al., 2011). The method also proposes an appended AM strategy for revascularization, in the hope to enhance appropriate wound healing in these challenging situations (Alexandrescu et al., 2011; Attinger et al., 2006 Taylor \& Pan, 1998).

\section{Material and methods}

Patients. From January 2003 until October 2010, a series of 28 limbs with threatening ischemic foot wounds in 26 diabetic and ESRD patients were retrospectively studied. All subjects were at high risk for major limb amputation with no feasible conventional arterial 
revascularizations. They were treated by hybrid (surgical and endovascular) deep calf veins arterialization following the AM concept. This method allows Selective Arterio-Venous Endoluminal Switch (the SAVES- technique, previously described by our group in the deep calf veins (Alexandrescu et al., 2011), following an AM strategy of perfusion (Attinger et al., 2001, 2006; Taylor \& Pan, 1998). Two patients received a staged bilateral intervention at eight and twelve months interval, respectively. The method's aim is to provide a pulsatile flow to the foot by selective bypass arterialization of one of the paired either anterior, posterior or peroneal deep calf veins (according the AM distribution), with synchronous devalvulation and endoluminal coil-exclusion of the collaterals. The group gathered specific presentations with unfeasible or previously failed arterial reconstrucions, including lack of superficial vein material or inappropriate tissues conditions for distal bypasses (including eventual arterializations in the superficial venous network). Severe ischemic wounds (Rutherford categories 5-6.) (Dayal \& Kent, 2005; Rutherford et al., 1997) confined to the foot (Wagner grades 3-4) (Driver et al., 2007) were noted in 22 limbs (79\%), whereas 6 (21\%) others presented complex below the knee trophic lesions. Advanced gangrene with irrecoverable tissue loss (Wagner grade 5 lesions) (Driver et al., 2007), preexisting severe cardiac insufficiency (LVEF $<30 \%$ ) and eventual disagreement of patients for this type of intervention, represented the major exclusion criteria.

There were 20 men and the mean age was 73.7 years (in the range 56-89). Nine (32\%) cases were insulin dependent.

Patient characteristics and risk factors are summarized in Table I:

\begin{tabular}{|c|c|c|}
\hline $\begin{array}{l}\text { PATIENTS CARACTERISTICS / RISK } \\
\text { FACTORS }\end{array}$ & Nr. Limbs $(n=28)$ & $(\mathrm{n} \%)$ \\
\hline Age $>70$ years & $\mathrm{n}=12$ & $43 \%$ \\
\hline Smoking & $\mathrm{n}=14$ & $50 \%$ \\
\hline Coronary Disease & $\mathrm{n}=27$ & $96 \%$ \\
\hline Ejection Fraction $-/<35 \%$ & $\mathrm{n}-18$ & $64 \%$ \\
\hline Cerebrovascular disease & $\mathrm{n}=10$ & $36 \%$ \\
\hline COPD & $\mathrm{n}=11$ & $29 \%$ \\
\hline LOCAL FEATURES IN TREATED & / LIMBS & \\
\hline 3 Crural Arteries Occluded & $n-27$ & $96 \%$ \\
\hline Incomplete or occluded pedal arch & $\mathrm{n}=22$ & $78 \%$ \\
\hline Failed previous femoral / distal bypass & $\mathrm{n}=15$ & $54 \%$ \\
\hline Spread of Calcifications $>5 \mathrm{~cm}$ & $n=24$ & $86 \%$ \\
\hline Associated Venuous Insufficiency $\mathrm{OK}$ & $\mathrm{n}=10$ & $35 \%$ \\
\hline Inferior Limb Neuropathy & $\mathrm{n}=26$ & $93 \%$ \\
\hline Osteomyelitis & $n-13$ & $46 \%$ \\
\hline Wagner score $>2$ & $\mathrm{n}=23$ & $82 \%$ \\
\hline
\end{tabular}

Table I. 
The technical features of the 28 combined surgical and endovascular angiosome-oriented interventions are described in Table II:

The technical features of the 28 combined surgical /endovascular procedures.

\begin{tabular}{|c|c|c|c|c|c|}
\hline \multicolumn{2}{|c|}{ Type of prosthetic bypass. } & \multicolumn{2}{|c|}{ Localisation of the targeted venosome } & \multicolumn{2}{|c|}{ Sites of collateral vein embolization } \\
\hline & & Anterior Tibial \& forefoot & $(n=6)$ & $\begin{array}{l}\text { TPt + collat. ATa. } \\
\text { TPa + collat. ATa. }\end{array}$ & $\begin{array}{l}(n=3) . \\
(n=3) .\end{array}$ \\
\hline \multirow{2}{*}{ FEMOKO - POPLITEAL (P3) } & \multirow{2}{*}{$(\mathrm{n}=17)$} & Posterior Tibial \& plantar/ heel & $(n=10)$. & ATa + collat. PTa. & $(n=10)$ \\
\hline & & Peroneal \& lateral ankle & $(n=1)$ & ATa+PTa+collat. Peroneal & $(n=1)$ \\
\hline \multirow[t]{3}{*}{ POPLITEO (P1) - POPLITEAL (P3) } & $(n=3)$. & Anterior Tibial \& forefoot & $(n=3)$ & PTa + Peroneal & $(n=3)$. \\
\hline & & & & TPt + collat. ATa & $(n=1)$ \\
\hline & & Anterior Tibial \& forefoot & $(n=2)$ & PTa + collat. ATa & $(n=1)$ \\
\hline \multirow[t]{4}{*}{ FEMORO - TIRIAL } & $(\mathrm{n}-6)$. & Posterior Tibial \& heel & $(n=3)$ & Peroneal+collat. PTa & $(n=1)$ \\
\hline & & & & Collat. PTa & $(n=2)$ \\
\hline & & Peroneal \& lateral ankle & $(n=1)$. & PTa + collat. Peroneal & $(n=1)$ \\
\hline & & Anterior Tibial \& forefoot & $(n=1)$ & PTa+Poroneal+collat. ATa & $(n=1)$ \\
\hline \multirow[t]{3}{*}{ POPLITEO - TIBIAL } & $(\mathrm{n}-2)$. & Posterior Thial \& plantar & $(n=1)$ & ATa+Peronealtcollat_PTa & $(n=1)$ \\
\hline & & $\mathrm{ATa}=$ Anterior Tibial artery & & \multirow{2}{*}{\multicolumn{2}{|c|}{ PTa $=$ Posterior Tibial artery }} \\
\hline & & TPt $=$ Tibio-Peroneal trunk & & & \\
\hline
\end{tabular}

Table II.

All patients were simultaneously followed in the nephrology-dialysis department. They underwent a preoperative complete inferior limbs arterial and venous Duplex scan, adding either DS-Arteriography (in our early experience) or preliminary Angio-CT assessment coupled to a per-operative angiography (in the recent years).

Complementary Duplex notification concerning the valvular competence and the anatomical distribution (the level of vein duplication) concerning the deep venous system were collected.

Following arterialization, adjuvant wound therapy was pursued in a multidisciplinary "diabetic-foot" clinic, according to each specific tissue defect presentation / Table III:

\begin{tabular}{|c|c|c|}
\hline ADJUVANT WOUND TREATMENT & $\begin{array}{c}\text { Nr. Iimbs } \\
(\mathrm{n}=28) .\end{array}$ & $(n \%)$ \\
\hline Vacuum-assisted wound closure & $n-8$ & $28 \%$ \\
\hline Biosynthetic skin substitutes & $\mathrm{n}=2$ & $7 \%$ \\
\hline Maggot therapy & $\mathrm{n}=5$ & $18 \%$ \\
\hline Hyperbaric oxygen therapy & $n-1$ & $3 \%$ \\
\hline Rotational skin flaps & $\mathrm{n}=1$ & $3 \%$ \\
\hline PACF Technology & $\mathrm{n}=2$ & $7 \%$ \\
\hline Epithelialization-stimulating dressings & $n-7$ & $25 \%$ \\
\hline Without local adjuvants: refuse or inability for treatment & $\mathrm{n}-2$ & $9 \%$ \\
\hline
\end{tabular}

Table III. 
Definitions. Clinical grading of the inferior limb ischemia was evaluated according to the revised criteria of SVS/ISCVS (Rutherford et al., 1997) and the TASC (II) recommendations (Norgreen et al., 2007). Other specific clinical findings were guided by the Wagner revised classification (Driver et al., 2007) and the UK peripheral neuropathy screening score (Young et al., 1993).

The technical success was considered if a direct arterialized axis starting from the iliac level through the selected deep calf veins till the peri-malleolar or foot level network was present after devalvulation and selective embolizations of venous side branches. This implied lack of deep vein narrowing or major steal phenomena, induced by venous tibial collaterals or perforators.

Limb salvage implied no requirement of major amputation and if the functional autonomy of the patient was recovered (walking or standing) despite eventually minor amputations (at the metatarsal or toe level).

Endpoints and statistical analysis. All results were reported in an intention to treat analysis. Patency, clinical success, limb salvage and patients survival rates were studied using the Kaplan-Meier life-table method at sequential intervals.

The surgical and endovascular "SAVES" method for deep calf vein arterializations. The "hybrid" technique for vascular reconstruction (Selective Arterio-Venous Endoluminal Switch - the "SAVES" method) followed a similar protocol, as previously described by our team (Alexandrescu et al., 2011). The pre-operative medication included a constant antiplatelet therapy (160 mg aspirin daily or clopidogrel $75 \mathrm{mg} /$ day). In this cohort, the treatment was already started in all patients before the procedure for previous miscellaneous cardio-vascular problems. General anaesthesia was applied in 21 cases (75\%), local anaesthesia and slight sedation in $6(21 \%)$, while sole local anaesthesic products were preferred in 1 (4\%) of interventions. In the first stage of the procedures (surgical), a classical protocol for femoro-infragenicular PTFE bypass was undertaken (Fig. $\mathbf{2}$ and $\mathbf{3 b}$ ).
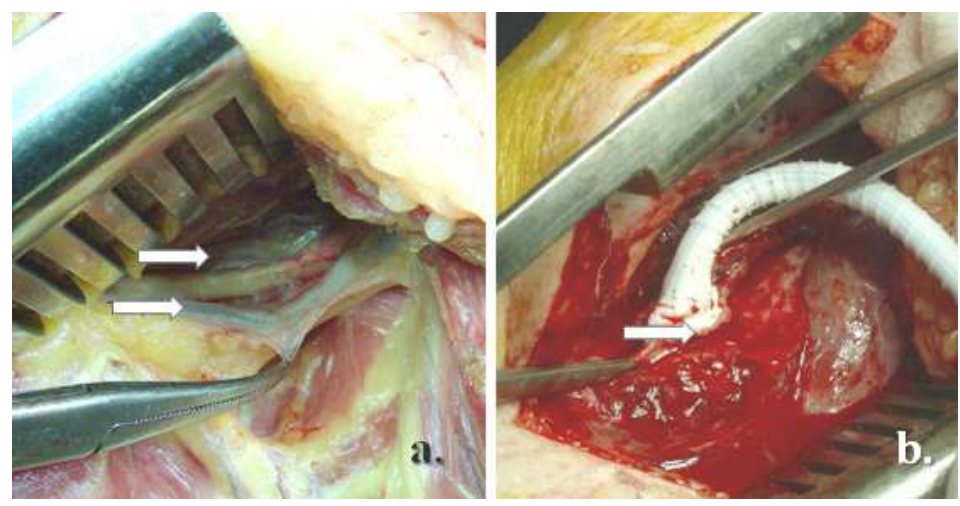

Fig. 2. Distal "PTFE- graft" anastomosis at the popliteal level:

a. The presence of a "twin popliteal veins" anatomical pattern white arrows),

b. Termino-lateral anastomosis as to arterialize one of the two popliteal veins in a femoro (arterial) - popliteal (venous) PTFE graft during the first stage of the procedure. The synthetic graft allows the passage of a long $6 \mathrm{~F}$ introducer from the groin, further enhancing the second stage of the intervention: selective devalvulation and collateral embolization of specific tibial deep veins, following the AM distribution. 


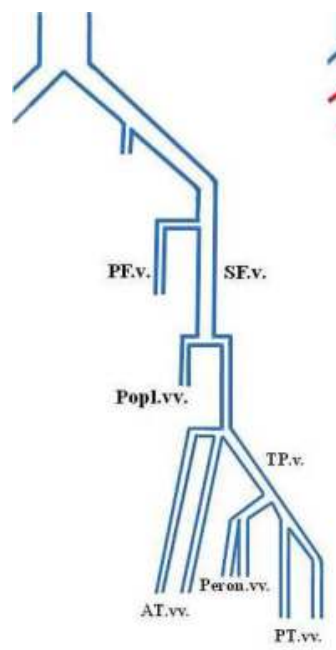

a.

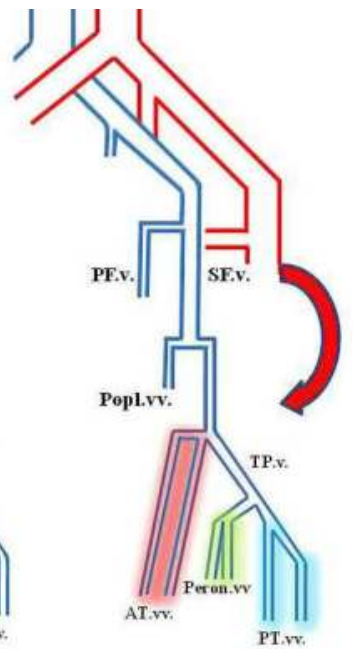

b.

Fig. 3. a) A brief illustration of the main deep venous trunks in the leg:

PFv: Profound Femoral vein,

SFv: Superficial Femoral vein,

Popl. vv: Popliteal veins,

AT. vv: Anterior Tibial veins

Peron. vv: Peroneal veins

PT. vv: Posterior Tibial veins

b) The red curved arrow: schematic arterial in-flow from the groin. Below the knee twin veins and their correspondent venosomes:

In red: appended Anterior Tibial Venosome,

In yellow: correspondent Peroneal Venosome,

In blue: adjacent Posterior Tibial Venosome.

The common femoral artery was usually the chosen in-flow vessel $(n=16)$ albeit the SFA $(n=$ $7)$ and the popliteal artery $(n=5)$ was seldom employed. The location of the distal anastomosis, to induce direct arterial flow toward the deep calf veins (Fig. 2), was planned upon the Duplex findings on the level of duplication (Table II) and topographical specificities of the wounds (the angiosomes distribution) (Attinger et al., 2001, 2006; Taylor et al., 1990,1998). This distal anastomosis was realised on one of the doubled deep veins in a termino-lateral $(n=23)($ Fig. 2$)$ or termino-terminal way $(n=5)$. In all the cases, $8 \mathrm{~mm}$ PTFE armed prosthesis $(n=21 /$ Distaflow BARD co. USA, and $n=7 /$ GORE Medical Products co.USA) were placed. Before clamping the femoral artery, a 2500 IU heparin amount was given in order to promote anticoagulation yet, minimizing possible interferences with the second procedural stage (endovascular), the collateral embolizations. The cephalad segment of the twin vein was ligated, while side anastomosis was chosen. Although the distal popliteal vein was found more often paired than single (Fig. 2 and 3) according to other similar observations (Wind et al., 1991), in ten cases (35\%) the distal anastomosis was performed directly in selected venous tibial trunks (Table II.) and oriented toward the main corresponding foot angiosome (venosome) (Fig. 1 and 3). After releasing the flow in the 
PTFE arterio-venous bypass, an $80 \mathrm{~cm} \mathrm{/} \mathrm{6-F} \mathrm{introducer} \mathrm{sheath} \mathrm{(Cook,} \mathrm{inc.} \mathrm{UK)} \mathrm{was}$ antegradely mounted via the common femoral artery traversing the prosthetic graft. A roadmapping of the infra-popliteal venous deep network was obtained, beyond the distal anastomosis. The competence of the deep valvular system was documented (often already affected by neuropathic "idiosyncratic deep venous distension" in this subset of patients) (Pureval et al., 1995). Although rarely needed, devalvulation was initially started by crossing each valve with a 0.035-inch hydrophilic guidewire (Terumo, Japan) and accomplished by the passage of the $6-\mathrm{F} 80 \mathrm{~cm}$ long introducer sheath (occasionally necessitating few "back and forth" co-axially over the wire movements) (Fig. 4a and 5a).

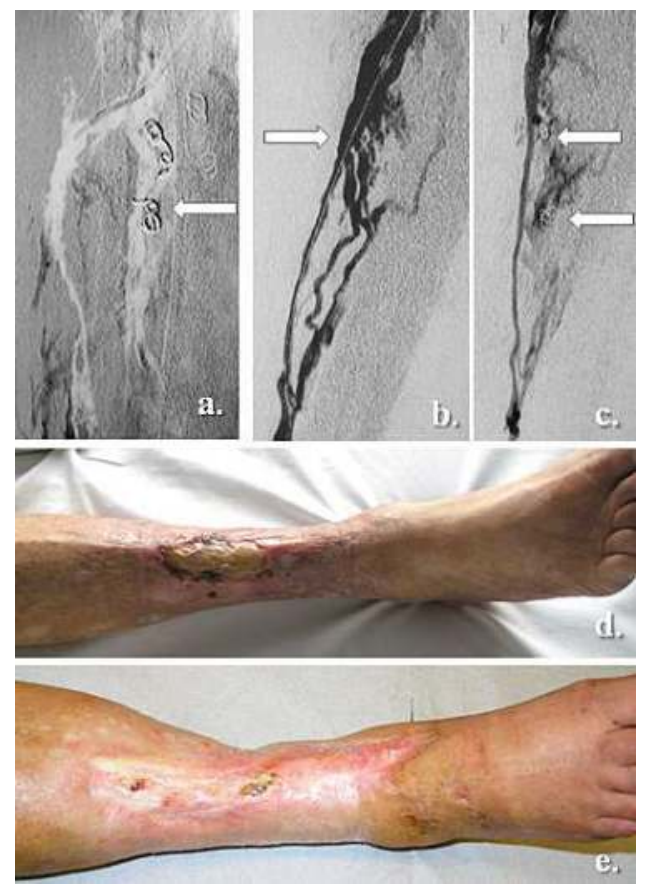

Fig. 4. Specific Anterior Tibial deep veins arterialization:

a. Initial selective embolization of the Posteriof Tibial and twin veins with peculiar canulation of the Anterior Tibial vein, enabling to direct the arterialization toward the Anterior Tibial angiosome and correspondent venosome.

b. Specific catheterization and devalvulation of the Anterior Tibial vein tovard the ankle,

c. The newly induced arterial flow in the Anterior Tibial venosome, after specific collateral embolization.

d. The initial clinical presentation featuring an extended ischemic and infected ulcer on the anterior tibial aspect of the calf.

e. The clinical outcome following specific anterior tibial veins arterialization, at seven months after multidisciplinary follow-up.

The long sheath was advanced until the ankle region in the angiosome-selected venous pathway. Contrast mapping demonstrated the principal collaterals or perforators of the chosen deep vein axis. Using a floppy tip 5-F vertebral or "Cobra 2-3" catheters (Cook inc., 
UK) or, in some other instances with a better adapted 4-F curved hydrophilic micro-catheter ("Slip-cath" selective catheter, Cook inc. UK), the main venous collaterals were selectively catheterized and occluded using coils embolization material (5-F "Tornado", "Nester" or stainless steel 5-8mm coils / Cook inc., Medical UK) (Fig. 4 a, b, c, and 5 a, b). These coils were delivered mainly using the "coaxial" technique (and seldom only by the "anchor" method) (White \& Pollak, 2006) in the principal deep venous ramifications. There was an average of $7.1(n=5-19)$ coils released per procedure. The side branches embolization stage was performed as distally as possible (Fig. $4 \mathbf{c}$ and $\mathbf{5 c}$ ), toward the clinical venosomelocation of the wounds (White \& Pollak, 2006). The progressing results were assessed by small contrast injections (Fig. 4c and 5c). Not all the collaterals were approachable during this stage of the procedure, particularly the medium-sized to small diameter veins, usually located in the peri-malleolar deep network (Fig. 5c). To avoid prolonged time and contrast consuming interventions, the selective branch embolizations were restricted below the ankle level, as the distal blood pressure measured through the 6-F introducer sheath edge exceeded $50 \mathrm{~mm} \mathrm{Hg}$. This observation allowed exclusion of residual CLI hemodynamic features (Norgreen et al., 2007; Rutherford et al., 1997). Hemostasis was directly performed at the arterial puncture level after the withdrawal of sheaths. All patients were prescribed aspirin $(160 \mathrm{mg} /$ day $)$ after the procedure, unless intolerant or previous treatment with clopidogrel, ticlopidin or oral anticoagulation, in which case these last ones were prolonged.
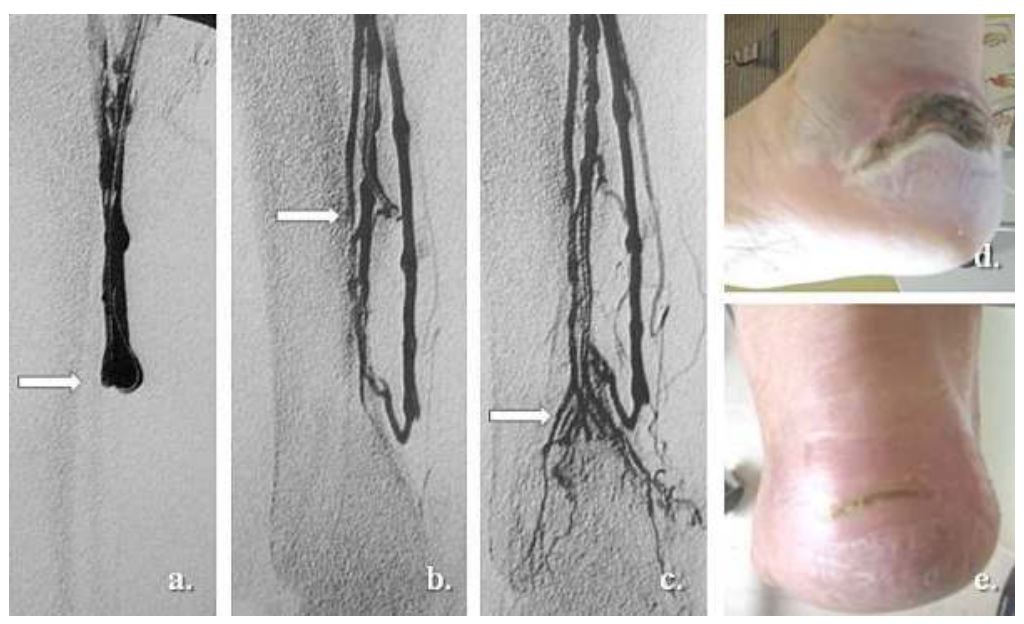

Fig. 5. Deep Posterior Tibial veins selective arterialization:

a. Devalvulation in the main vein trunk using the 0.035 -inch guidewire and the passage of the $6 \mathrm{~F}$ long introducer sheath.

b. Selective "coaxial" embolization of the main deep vein collaterals owing a $5 \mathrm{~F}$ curved microcatheter.

c. Regain of the arterial flow in the vein collaterals around the heel targeting the medial calcaneal angiosome (and its appended venosome).

d. The initial heel neuro-ischemic wound.

e. Clinical result at five months providing the same multidisciplinary "diabetic foot" team surveillance. 
Follow-up. In the post-operative period, patients were assessed by periodical clinical and hemodynamic (duplex scan) evaluations, focusing on tissue healing, bypass patency and the presence of arterial waves in the ankle or foot deep veins. Information was collected one month after discharge and every 6 months thereafter. In cases showing clinical tissue deterioration as primary end-point, corroborated by corresponding duplex findings, further Angio-CT or MRI evaluation was undertaken. Mean follow-up was 23.3 months (in the range 1-68 months).

\section{Results}

The initial technical success was achieved in $21 / 28$ limbs (75\%) with $96 \%$ corresponding thirty-day peri-operative mortality rate (one patient died from myocardial infarction). In seven instances, the procedure could not follow the scheduled protocol. In 2 cases, the distal venous anastomosis of the PTFE graft was unachievable either in a context of extensive fibrosis (multiple previous interventions) or by substantial inflammation. In 2 others, unexpected wall laceration of the selected venous conduit during the devalvulation stage required hemostasis by direct embolization of these veins. Since alternative deep veins arterializations without AM guidance were used, these cases were categorized as technical failures. There were 3 other situations when the distal embolization of collaterals could not be achieved: in two limbs, a rich network of fine branches with sharp angle and retrograde emergence rendered difficult all endovascular manoeuvres, while in other case the embolization stage was discontinued following an intolerance to contrast agents. For the whole 7 technical failures, 4 compulsory arterializations (non angiosomes-oriented) of miscellaneous deep or superficial veins, one minor and 2 major amputations were requested. During the first year of follow-up, there were 2 graft occlusions. In both instances, irregularities in the postoperative medication (modest compliance of patients) were noted. After eight months of surveillance one of these 2 limbs showed however, a correct tissue recovery despite the PTFE thrombosis, while major amputation was inevitable for the other.

The cumulative primary and secondary patency were (+/-SEM): $71 \%(+/-9 \%), 59 \%(+/-$ $10 \%)$ and $59 \%(+/-10 \%)$, at 12, 24 and 36 months, respectively. Limb salvage showed: $86 \%$ $(+/-7 \%)$ at one year and steady $77 \%(+/-10 \%)$ afterwards, while the clinical success was: $82 \%(+/-7 \%), 71 \%(+/-10 \%)$ and $71 \%(+/-10 \%)$ at identical time intervals (Fig. 6).

Deep venous system reflux was assessed in 19/28 (68\%) limbs, whereas in only 10/28 (35\%) previous evidence for clinical venous insufficiency was available. In all 28 treated limbs deep vein duplications were documented (preoperative Duplex) as follows: 20 in the distal popliteal (71\%) (Fig. 2), 5 in the proximal popliteal (18\%) and 3 concerning the superficial femoral (12\%) deep veins. The overall 30-day peri-operative complication rate was $21 \%$ (6/28cases). Major complications were noted in three cases (11\%): there were two temporary cardiac deficiencies after the initiation of the arterio-venous flow compensated by inotropic agents and diligent medical treatment and one secondary compartmental syndrome coupled to venous gangrene, ending in inevitable amputation. There were 3 other minor complication represented by 2 venous branch perforations of the collaterals with self limiting local effects and one causing secondary limb swelling, that needed prolonged postoperative physiotherapy before ambulation. Following the evoked AM strategy and appended venosome-model for arterialization (Fig. 1), we have noted: 10 limbs treated by preferential anterior tibial veins arterialization (trophic lesions located on the anterior leg 
and ankle, the forefoot, dorsum of the toes and foot) (Fig. 4), 16 others having revascularizations in the posterior tibial veins territory (ulcers of the medial calcaneal, plantar, hallux, medial malleolar and Achillean teguments) (Fig. 5), while the remnant 2 targeted a dominant peroneal in-flow (wounds located in the lateral calcaneal and lateral malleolar territories) (Table II.).
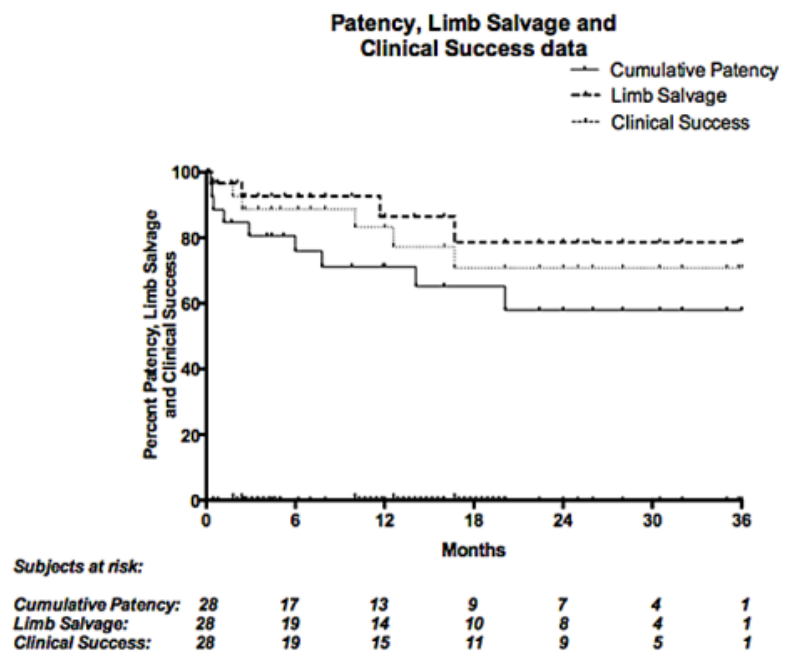

Fig. 6. Patency, Limb Salvage and Clinical Success statistical data.

Although complete healing with or without minor amputations was documented in 15 treated limbs (54\%) (Fig. 4e and 5e), notable trends for tissue recovery without complete cicatrization were observed in 7 others (25\%). Major amputations were however, inevitable in the remnant 6 presentations (21\%). Cyclic relapses of the wounds, albeit without ischemic Duplex features were documented in $11(39 \%)$ cases, mostly between the $10^{\text {th }}-15^{\text {th }}$ months of follow-up. These limbs were invariably associated a severe neuropathic background.

In the whole group of patients, six $(21 \%)$ major amputations for miscellaneous clinical reasons were documented ( 2 technical failures, 2 major complications, 1bypass thrombosis and 1 progressively irreversible forefoot sepsis).

The thirty-day peri-operative mortality rate was $0 \%$. The cumulative survival rates were $93 \%, 66 \%$ and $38 \%$ at 12,24 and 36 months, respectively.

\section{Discussion}

The renal patient presents with unanimously recognized severe CLI features and consequent difficult revascularization patterns (Casserly, 2008; Conrad et al., 2009; Leers et al., 1998; Norgreen et al., 2007). A vast amount of contemporary literature shows the poor outcome commonly noted after surgical or endovascular arterial reconstruction in these patients (Arvela et al., 2010; Black et al., 2005; Casserly, 2008; Conrad et al., 2009; Leers et al., 1998). As the revascularization seems however feasible, particularly aggressive atherosclerosis coupled to long segment chronic occlusions, calcifications and depleted run-off, make further arterial 
patency and limb preservation quite questionable in ESRD subjects (Arvela et al., 2010; Black et al., 2005; Casserly, 2008; Leers et al., 1998). These poor clinical results are often associated with a high co-morbidity and mortality, independently from diabetes and other cardio-vascular risk factors (Leers et al., 1998; Mlekusch et al., 2004; Norgreen et al., 2007). Similar observations were described in the diabetic CLI context that adds the metabolic and neuropathic background, local sepsis, poor immune response and variable amounts of foot tissue loss (Abou-Zamzam et al., 2007; A pelqvist et al., 1993; Norgreen et al., 2007).

Moreover, the diabetic CLI "macro-angiopathic" atherosclerosis is characterised by enhance more aggressive and more distal occlusive lesions, with preferential tropism in the tibial trunks (Apelqvist et al., 1993; Dormandy et al., 1999; Faglia et al., 2007 Norgreen et al., 2007). A synchronous functional microcirculatory affectation induced by both neuropathic and septic entanglement, was also witnessed in this multifaceted pathology of the diabetic foot (Apelqvist et al., 1993; Boulton et al., 2006; Edmonds, 2008). Despite soaring progresses in technology and aggressive follow-up, long-term limb preservation seems however inferior in diabetic - ESRD subjects compared to other CLI patients, mainly due to extended infragenicular arterial thrombosis, calcifications and poor distal foot runoff (Abularrage et al., 2010; Dormandy et al., 1999).

While non-diabetic subjects seem to express intima-layer, eccentric and patchy wall arterial calcifications, prevailing in the coronary also the peripheral vessels (the "type $I$ » calcifications) (Irvin \& Guzman, 2009), the diabetic also ESRD patients have media-layer, concentric and rather continuous wall calcifications (the "Mönckeberg sclerosis" or "type II » calcifications) (Irvin \& Guzman, 2009). These particularly dense "type II » calcific deposits featuring the below-knee arterial trunks were independently associated with more severe CLI presentations (Irvin \& Guzman, 2009 ; Leskinen et al., 2002), requiring additional technical challenges (Abou-Zamzam et al., 2007; Alexandrescu et al., 2011; Casserly, 2008; Leers et al., 1998) and consequent higher technical failures. They were also connected with low patency and discouraging limb loss rates (Casserly, 2008; Combe et al., 2009; Leers et al., 1998; Ohtake et al., 2011).

The reported 1-year survival rate after major amputations ranges between $50 \%-60 \%$ and seems to be worse for patients undergoing above- the-knee versus below-the-knee interventions (Dormandy et al., 1999; Toursarkissian et al., 2002). Despite undeniable progresses in both surgical and endovascular approaches, in about $14 \%-20 \%$ of patients featuring severe crural and pedal occlusive disease, neither of the available techniques can afford appropriate distal arterial supply, resulting amputation (Abou-Zamzam et al., 2007; Apelqvist et al., 1993; Combe et al., 2009 Norgreen et al., 2007; Toursarkissian et al., 2002). This assertion seems particularly valid regarding the ESRD subjects suffering from CLI (Abou-Zamzam et al., 2007; Apelqvist et al., 1993; Arvela et al., 2010; Black et al., 2005; Casserly, 2008; Conrad et al., 2009).

Complementary efforts for limb preservation were achieved in the plastic reconstructive surgery field, by applying the AM policy for perfusion in tissue rebuilding. The concept delineates the human body in specific 3D blocks of tissue, fed by peculiar arterial and venous bundles of blood supply (Attinger et al., 2001, 2006; Taylor et al., 1990, 1998). Originally pioneered for the pediculated flaps techniques, the AM strategy (Attinger et al., 2006; Taylor et al., 1998) was also applied to improve healing in lower limb ischemic ulcers (Alexandrescu et al., 2008; Neville et al., 2009; Varela et al., 2010; Setacci et al., 2010). Based on the anatomical studies of Taylor (Taylor et al., 1990, 1998) and Attinger (Attinger et al., 2001, 2006), new preferential strategies for vascular access, revascularization or amputation 
were described. Schematically, in the foot and lower ankle were initially allocated 5 angiosomes (Attinger et al., 2006; Taylor et al., 1998) depending on the three main tibial trunks : the anterior, the posterior tibial and the peroneal arteries. A succinct exemplification of the corresponding skin sectors is showed in Fig. 1. Each angiosome encompasses an arterial (arteriosome) and correspondent venous (venosome) participation (Taylor et al., 1990, 1998). Particularly for this chapter, a specific venosome-orientation (concerning the venous facet of each angiosome) (Alexandrescu et al., 2011; Taylor et al., 1990) in deep calf veins arterialization was designed (Fig. $\mathbf{3 b}$ ).

Deep veins arterialization in ESRD and diabetic CLI patients may offer the advantage to direct flow in the deep calf venous conduits spared from typical type II calcifications (Irvin \& Guzman, 2009) and extended chronic occlusions (Lu et al., 2006; Toursarkissian et al., 2002). This may enable to deliberately choose specific distal territories (Fig. 4 and 5) to be reperfused (Alexandrescu et al., 2011). It may also fit selected extreme situations for limb salvage, despite irrecoverable occlusions of the arterial network (Alexandrescu et al., 2011; Lu et al., 2006). The concept of venous arterialization to treat advanced CLI presentations has emerged as an extreme therapeutic alternative in cases with impracticable conventional arterial reconstructions (Jacop et al., 1999; Lu et al., 2006). In Table I, are schematized the main features of the patients addressed for this technique. The majority of arterializations for "hopeless" CLI presentations intended for amputation were described in the literature using the available superficial venous system (Jacop et al., 1999; Lengua et al., 2001; Lu et al., 2006). A growing number of contemporary reports seem to provide rather encouraging (Lengua et al., 2001; Lu et al., 2006) than pessimistic results (Matzke et al., 1999) concerning this evolving technique. In most of the published studies, the arterialized venous conduit and the distal anastomosis are located at different levels in the superficial saphenous system, usually adding destruction of the appended valves (Lengua et al., 2001; Lu et al., 2006; Ozbek et al., 2005). In this setting, the arterialization of the superficial venous network carries however, some possible limitations: a) its availability (particularly in ESRD, diabetic CLI patients with huge dialysis-access and cardio-vascular surgical past) and b) the presence of surrounding inflammation, sepsis and edema. This latest factor affects the "quality" of the surounding venous bed and hampers further graft preparation or its accessibility to the distal foot anastomosis (Alexandrescu et al., 2011; Lu et al., 2006). Furthermore, in these situations the eventual affiliation of the AM concept may be problematic, as the saphenous network offers only limited choices in targeting specific areas for foot arterializations (Alexandrescu et al., 2011). Only odd reports are focusing until yet, on alternative deep veins arterialization for CLI limb salvage. This strategy was however previously proposed, either in experimental (Ozek et al. 1997) or as staged interventions (Chen et al., 1998; Lu et al., 2006), without systematic valvular avulsion.

Although rational, the genuine concept for distal valves destruction in newly arterializated venous conduits, has give rise to different techniques assembling either metallic olives, retrograde balloon PTA or 0.035-inc guidewire-enhanced valvular disruption, sustained or not by Fogarty catheters (Lu et al., 2006). Other authors have promoted the sole hydraulic effect of the new arterial pulsatile flow, as to be adequate enough for counteracting the venous valves barrier, especially in the deep venous circulation (Chen et al., 1998; Krisnan \& Rayman, 2008; Lu et al., 2006). In spite of recent supportive observations (44), this latest hypothesis remains controversial (Lu et al., 2006).

In the author's group experience, we stressed the concept of restoring limb perfusion in the deep venous pathway, for untreatable ESRD ischemic lesions deemed for "classical" arterial 
reconstructions. Most of these cases featured characteristic infrapopliteal extensive occlusions (Casserly, 2008; Conrad et al., 2009; Norgreen et al., 2007; Toursarkissian et al., 2002) and calcifications (Alexandrescu, 2009; Irvin \& Guzman, 2009; Krisnan \& Rayman, 2008; Leskinen et al., 2002), when all types of conventional reconstructions have previously failed or were impracticable (Table I.).

In this setting, bypassing the deep venous network towards the distal foot circulation seemed unconditioned neither by tegumental integrity, swelling or tissue infection, nor by the availability of saphenous versus other autologous bypass conduits. The current calf venous duplication (Wind et al., 1991), may offer the possibility to enhance precise arterializations (Fig. 3-5) in one of the twin tibial veins (Alexandrescu et al., 2011), by following a specific AM strategy (Alexandrescu et al., 2011; Taylor et al., 1990). To achieve this aim, acquiring effective valvular incompetence also proved to be indispensable in our experience. This was either primary induced by the first crossing of the 0.035-inch hydrophillic guidewire (Fig. 5), or complementary obtained with the passage of a $6-\mathrm{F}, 80 \mathrm{~cm}$ long introducer sheath through the distal deep vein (Fig. $\mathbf{4 b}$ and $\mathbf{5 b}$ ). Nevertheless, the lack of residual valvular tensile stress was documented in all the cases by injecting a small amount of contrast before proceeding to the embolization stage. A preexistent valvular incompetence by vein walls enlargement was witnessed in more than $25 \%$ of cases, oftentimes without previous evidence for chronic venous insufficiency. This finding may correlate the presence of up to $93 \%$ neuropathic limbs in this cohort (Table I.), that exhibit the previously described "idiosyncratic deep venous distension" context (Alexandrescu et al., 2011; Boulton et al., 2006; Edmonds, 2008; Pureval et al., 1995). The existence of neuropathyassociated capillary shunting in diabetic ESRD subjects (Krisnan \& Rayman, 2008; Pureval et al., 1995), seems to allow local redistribution of the dermal, sub-dermal and muscular blood flow and by additional ascendant venous collectors (Calota et al., 2007). This makes possible the blood mass transfer from deep calf to the surface, especially as moderate venous hypertension appears (Calota et al., 2007; Edmonds, 2008; Krisnan \& Rayman, 2008). Duplication in tibial veins may allow the arterialized flow to be deliberately oriented towards specific ulcerated zones of the distal leg (Alexandrescu et al., 2011; Taylor et al., 1990) according to the AM policy (Fig. 1 and 2). First described by Taylor et al. (Taylor et al., 1990, 1998), the "angiosomes model" for perfusion was further developed by Attinger et al. (Attinger et al., 2001, 2006) also in the plastic reconstructive surgery field. Although with limited contemporary evidence for CLI applications at the present time, this concept seems to gain more acceptance in the limb salvage domain (Neville et al., 2009; Varela et al., 2010; Setacci et al., 2010) and represents one of the current concerns of our multidisciplinary diabetic "foot-team" (Alexandrescu et al., 2008, 2009, 2011). According to their initial description, each angiosome encompasses twin arteriosomes and venosomes for blood supply, all being interconnected in a vast compensatory system (the"choke vessels") (Attinger et al., 2006; Taylor et al., 1998). The arterial side of this "rescue network" relying on adjacent angiosomes seems particularly damaged in ESRD/diabetic patients exhibiting peculiar medium-sized collaterals depletion by aggressive atherosclerosis joined to small arterial septic thrombosis (the already reported "end artery occlusive disease" pattern) (O'Neal, 2008). Unlike the arteries, deep calf veins and collaterals seem less affected by this occlusive process (Alexandrescu et al., 2011; Krisnan \& Rayman, 2008). This important aspect may enable deep vein arterialization to access specific leg territories (angiosomes), throughout their appended venous communicants (venosomes), in areas although deprived from direct arterial connections (Alexandrescu et al., 2011). 
We used the venosomes orientation (Taylor et al., 1990) joined to the SAVES technique (Alexandrescu et al., 2011) in all these marginal candidates for common revascularizations and observed correct healing with or without minor amputations in 15 treated limbs (54\%). Notable trends for tissue recovery however without complete cicatrization were documented in 7 others (25\%). Major amputation were inevitable in the remnant 6 presentations $(21 \%)$.

It has been stipulated that the "venosomes" allocation may be prone to anatomical variations (Taylor et al., 1990) according to the individual distribution of the deep venous system (Calota et al., 2007; Taylor et al., 1990; Wind et al., 1991) (Fig. 3). We believe that systematic preoperative Duplex assessment joining « on table » road-mapping, may provide important information in detecting these venous pecularities $(26 \%$ limbs in our cohort). We also observed that staged embolizations of the major vein collaterals were technically more demanding in the posterior tibial territory (Fig. 5), by steady large perforators or communicants, sometimes appointing sharp retrograde emergences with more arduous cannulation.

All treated patients expressed discrete to moderate lower limb edemas after arterializations. This phenomenon showed generally a spontaneous resolution during the postoperative first month. Similar observations in dedicated literature suggest that the more distal the location of the outflow anastomosis in long arterio-venous fistulas (femoro-infrapopliteal in our technique), the higher likelihood to enhance a better cardiac tolerance (Lengua et al., 2001; Ozek et al. 1997).

As noticed, in one case (4\%) persistent limb swelling joining calf compartmental syndrome and venous gangrene were documented, unfortunately ending with major amputation. In two other cases (8\%), cardiac insufficiency symptoms were perceived: one precocious and reversible manifestation (in the 30-day complications subset) and one insidious and retarded presentation (two months after the procedure), in a severe and inoperable coronary context.

The study presented in this chapter may express some clear limitations: beyond its retrospective nature and the small number of cases included, the results in terms of limb salvage are not easy to be compared with other series of conventional arterial reconstructions or venous arterializations, since the technique itself and the selection criteria are different.

In addition, the "SAVES" method represent only an evolving therapeutic option, since specific difficulties and related complications (notably the collateral embolization stage), may be subject for further technical improvements. A larger clinical experience and skills, joining more sophisticated devices for endovascular navigation and collateral occlusion (like modular micro-catheters, specific pro-thrombotic substances or embolic microspheres) may probably contribute to further technical refinements. Finally, to accurately evaluate and compare limb preservation in this subset of diabetic and renal patients oftentimes implies (beyond reestablishing limb perfusion) the undeniable implication of multi-disciplinary team surveillance (Abularrage et al., 2010; Alexandrescu et al., 2008; Apelqvist et al., 1993; Boulton et al., 2006; Driver et al., 2007; Edmonds, 2008; Norgreen et al.).

\section{Conclusion}

Deep calf venous arterialization (the SAVES-method) may represent an extreme alternative for limb salvage in selected, inoperable presentations for conventional arterial 
revascularization. The association of an angiosome strategy seems, at this stage of the available clinical experience, a possible useful method to enhance distal ulcer healing. Larger studies, providing comparative and randomized data are thus needed, as to ascertain these preliminary observations.

\section{Acknowledgments}

We would like to acknowledge in the first place all the members of the "Dialysis and Nephrology » department, also all those exercing a constant multidisciplinary activity in our institutional "Diabetic-Foot Group".

Equal acknowledgements the Princess Paola Hospital's radiology, cardiology and endocrinology departments for their assiduous assessment and punctual support in managing these challenging cases.

\section{References}

Abou-Zamzam AM Jr, Gomez NR, Molkara A, Banta JE, Teruya TH, Killeen JD, et al. A prospective analysis of critical limb ischemia: factors leading to major primary amputation versus revascularization. Ann Vasc Surg. 2007; 21(4): 458-463.

Abularrage CJ, Conrad MF, Hackney LA, Paruchuri V, Crawford RS, Kwolek CJ, et al. Longterm outcomes of diabetic patients undergoing endovascular infrainguinal interventions. J Vasc Surg. $2010 ; 52$ : 314-322.

Alexandrescu V, Hubermont G, Philips Y, Guillaumie B, Ngongang C, Vandenbossche P, et al. Selective angioplasty following an angiosome model of reperfusion in the treatment of Wagner 1-4 diabetic foot lesions: practice in a multidisciplinary diabetic limb service. J Endovasc Ther. 2008; 15: 580-593.

AlexandrescuVA.Commentary:Below-the-ankle subintimal angioplasty: how far can we push this application for lower limb preservation in diabetic patients? J Endovasc Ther. 2009;16: 617-8.

Alexandrescu V, Hubermont G, Vincent G. Diabetic neuro-ischemic foot wounds: does primary angioplasty following an angiosome model of perfusion can improve the fate of minor amputations and influence the global limb preservation rates? In: Advances in Medicine and Biology (Vol. 15) N.Y. Nova Science Publish. 2011: 17-37.

Alexandrescu V, Ngongang C, Vincent G, Ledent G, Hubermont G. Deep calf veins arterialization for inferior limb preservation in diabetic patients with extended ischaemic wounds, unfit for direct arterial reconstruction: preliminary results according to an angiosome model of perfusion. Cardiovasc Revasc Medicine. 2011;12: 10-19.

Andreoli M, Galli G, Arienzo A, Nora A, Tedoli M, Guidetti G, et al. Prevention and therapy of critical ischemia in hemodialyzed patients. G Ital Nefrol. 2008;26, Suppl 45: S28S31.

Apelqvist J, Larsson J, Agardh CD. Long-term prognosis for diabetic patients with foot ulcers. J Intern Med. 1993;233(6):485-91.

Arvela E, Soderstrom M, Korhonen M, Halmesmaki K, Alback A, Lepantalo M, et al. Finnvasc score and modified Prevent III score predict long-term outcome after infrainguinal surgical and endovascular revascularization for critical limb ischemia. J Vasc Surg. 2010; 52: 1218-1225. 
Attinger CE, Evans KK, Bulan E, et al. Angio- somes of the foot and ankle and clinical implications for limb salvage: reconstruction, incisions and revascularization. Plast Reconstr Surg. 2006;117(7 Suppl):261S-293S.

Attinger CE, Cooper P, Blume P, et al. The safest surgical incision and amputations applying the angiosomes principle and using the Doppler to assess the arterialarterial connec- tions of the foot and ankle. Foot Ankle Clin North Am. 2001; 6:745801.

Black JH, LaMuraglia GM, Kwolek CJ, Brewster DC, Watkins MT, Cambria RP. Contemporary results of angioplasty-based infrainguinal percutaneous interventions. J Vasc Surg. 2005; 42: 932-939.

Boulton AJM, Armstrong DG. The diabetic foot. In : Clinical diabetes, translating research into practice. Philadelphia, Saunders Elsevier, 2006 : 179-195.

Bradbury AW, Adam DJ, Bell J, Forbes JF, Fowkes FG, Gillespie I, et al. Bypass versus angioplasty in severe ischaemia of the leg (BASIL) trial: An intention to treat analysis of amputation-free and overall survival in patients randomized to a bypass surgery-first or balloon angioplasty-first revascularization strategy. J Vasc Surg. 2010; 51(5 Suppl): 5S-17S.

Calota F, Mogoanta S, Intorcaciu M, Pasalega M, Popescu CF, Vasile I, et al. The venous system of the lower limbs. Rom J Morphol Embriol. 2007; 48(4): 355-360.

Casserly IP. Interventional management of critical limb ischemia in renal patients. Adv Chronic Kidney Dis. 2008;15(4): 384-395.

Chen XS, Lin T, Chen DL, Guan YB. Venous arterialization of posterior tibial vein channel for extensive arterial occlusion of lower extremities. J Surg Concepts Pract. 1998; 3:219-221.

Combe C, Albert JM, Bragg-Gresham JL, Angreucci VE, Disney A, Fukuhara S, et al. The burden of amputation among hemodialysis patients in the Dialysis Outcomes and Practice Patterns Study (DOPPS). Am j Kidney Dis. 2009; 54: 680-692.

Conrad MF, Kang J, Cambria RP, Brewster DC, Watkins MT, Kwolek CJ, et al. Infrapopliteal balloon angioplasty for the treatment of chronic occlusive disease. J Vasc Surg. 2009, 50(4): 799-805.

Dayal R, Kent C. Standardized reporting practices. In Rutherford Vascular Surgery $6^{\text {th }}$ edition. Philadelphia. Elsevier Saunders Inc. 2005: 41-52.

Driver V, Landowski MA, Madsen JL. Neuropathic Wounds: The diabetic wound. In: Acute and Chronic Wounds-Current Management Concepts. Philadelphia, by Mosby Elsevier Inc. 2007: 307-336.

Dormandy J, Heek L, Vig S. Major amputations: clinical patterns and predictors. Semin Vasc Surg. 1999;12:154-161.

Edmonds M. A natural history and framework for managing diabetic foot ulcers. Br J Nurs, 2008, 17(11): S20, S22, S24-S29.

Faglia E, Clerici G, Caminiti M, Quarantiello A, Curci V, Morabito A. Predictive values of transcutaneous oxygen tension for above-the- ankle amputation in diabetic patients with critical limb ischemia. Eur J Vasc Endovasc Surg. 2007(33):731-736.

Irvin CL, Guzman RJ. Matrix metalloproteinases in medial arterial calcification: potential mechanisms and actions. Vascular. 2009. 17, Suppl 1; S40-S44. 
Jacop S, Nassef A, Belli AM, Dormandi JA, Taylor RS. Vascular surgery society of Great Britain and Ireland: distal venous arterializations for nonreconstructable arterial disease. Br J Surg. 1999;86(5):694-698.

Krisnan SM, Rayman G. Microcirculation and the diabetic foot. In: "The foot in diabetes" $4^{\text {th }}$ edition. London. Wiley \& Sons Ltd, 2008: 41-51.

Leers SA, Reifsnyder T, Delmonte R, Caron M. Realistic expectations for pedal bypass grafts in patients with end-stage renal disease. J Vasc Surg. 1998;28(6):976-980.

Lengua F, La Madrid A, Acosta C, Barriga H, Maliqui C, Arauco R et al. Arterialization of the distal veins of the foot for limb salvage in arteritis. Technique and results. Ann Chir. 2001;126:629-638.

Leskinen Y, Salenius JP, Lehtimaki T, Huhtala H, Saha H. The prevalence of peripheral arterial disease and medial arterial calcification in patients with chronic renal failure: requirements for diagnostics. Am J Kidney Dis. 2002;40: 472-479.

Lu XW, Idu MM, Ubbink DT, Legemate DA. Meta-analysis of the clinical effectiveness of venous arterializations for salvage of critically ischaemic limbs. Eur J Vasc Surg. 2006;31:493-499.

Matzke S, Pitkanen J, Lepantalo M. Does saphenous vein arterializations prevent major amputation in critical leg ischemia? A comparative study. J Cardiovasc Surg. (Torino) 1999;40:845-847.

Mlekusch W, Exner M, Sabeti S, Amighi J, Schlager O, Wagner O, et al. Serum creatinine predicts mortality in patients with peripheral artery disease: infuence of diabetes and hypertension. Atherosclerosis. 2004; 175 (2): 361-367.

NevilleRF, Attinger CE, Bulan EJ, Ducic I, Thomassen M, Sidawy AN. Revascularization of a specific angiosome for limb salvage: does the target artery matter? Ann Vasc Surg. 2009; 23(3): 367-373.

Norgreen L, Hiatt WR, Dormandy JA, Nehler MR, Harris KA, Fowkes FGR on behalf of the TASC II Working Group. Inter-Society Consensus for the management of peripheral arterial disease (TASC II.). Eur J Vasc Endovasc Surg. 2007; 33, Suppl.1:S32-55.

Ohtake T, Oka M, Ikee R, Mochida Y, Ishioka K, Moryia H, et al. Impact of lower limbs' arterial calcification on the prevalence and severity of PAD in patients on hemodialysis. J Vasc Surg. 2011; 53: 676-683.

O'Neal LW. Surgical pathology of the foot and clinicopathologic correlations. In: Levin and O'Neal's The Diabetic Foot. Philadelphia, Mosby Elsevier. 2008: 367-401.

Ozbek C, Kestelli M, Emrecan B, Ozsoyler I, Bayatli K, Yasa H, et al. A novel approach: ascending venous arterialization for atherosclerosis obliterans. Eur J Vasc Endovasc Surg 2005; 29:47-51

Ozek C, Zhang F, Lineaweaver WC, Chin BT, Newlin L, Eiman T, et al. Arterialization of the venous system in a rat lower limb model. Br. J Plast Surg. 1997; 50(6): 402-406.

Pureval TS, Goss DE, Watkins PJ, Edmonds ME. Lower limb venous pressure in diabetic neuropathy. Diabetes Care. 1995; 18(3): 377-338.

Randon C, Jacobs B, De Ryck F, Vermassen F. Angioplasty or primary stenting for infrapopliteal lesions: results of a prospective randomized trial. Cardiovasc Intervent Radiol. 2010; 33(2): 260-269. 
Rutherford RB, Baker JD, Ernst C, Johnston KW, Porter JM, Ahn S, et al. Recommended standards for reports dealing with lower extremity ischemia : revised version. $J$ Vasc Surg. 1997; 26(3): 517-38. Erratum in: J Vasc Surg. 2001; 33(4): 805.

Setacci C, De Donato G, Setacci F, et al. Ischemic foot: definition, etiology and angio- some concept. J Cardiovasc Surg (Torino). 2010; 51: 223-231.

Taylor GI, Caddy CM, Watterson PA, Crock JG. The venous territories (venosomes) of the human body: experimental study and clinical implications. Plast Reconstr Surg. 1990;86(2):185-213.

Taylor GI, Pan WR. Angiosomes of the leg: anatomic study and clinical implications. Plast Reconstr Surg. 1998; 102(3): 599-616.

Toursarkissian B, Shireman PK, Harrison A, D'Ayala M, Schoolfield J, Sykes MT. Major lower- amputation: contemporary experience in a single veterans affairs institution. Am Surg. 2002;68:606-610.

Varela C, Acín F, de Haro J, Bleda S, Esparza L, March JR. The role of foot collateral vessels on ulcer healing and limb salvage after successful endovascular and surgical distal procedures according to an angiosome model. Vasc Endovascular Surg. 2010; 44(8): 654-660.

White RI, Pollak JS. Controlled delivery of pushable fibered coils for large vessel embolotherapy. In: Vascular Embolotherapy a comprehensive approach, Volume 1, general principles, chest, abdomen and great vessels. Springer, 2006: 35-43.

Wind GG, Valentine RJ. Popliteal artery. In: Anatomic exposures in vascular surgery. Baltimore: William\&Wilkins, 1991: 373-410.

Young MJ, Boulton AJ, Macleod AF, Williams DR, Sonksen PH. A multicenter study of the prevalence of the diabetic peripheral neuropathy in the United Kingdom hospital clinic population. Diabetologia. 1993; 150-154. 


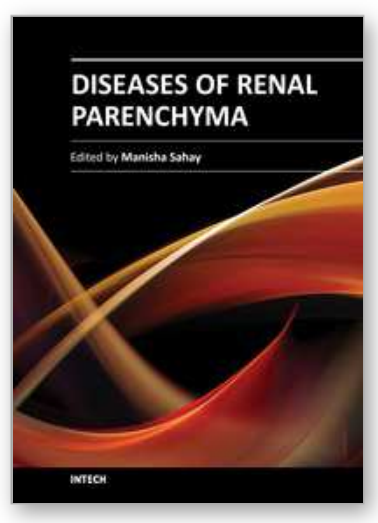

\author{
Diseases of Renal Parenchyma \\ Edited by Prof. Manisha Sahay
}

ISBN 978-953-51-0245-8

Hard cover, 304 pages

Publisher InTech

Published online 16, March, 2012

Published in print edition March, 2012

Clinical nephrology is an evolving speciality in which the amount of information is growing daily. This book gives quick access to some important clinical conditions encountered in nephrology including the diseases of glomeruli, tubules and interstitium. It presents the latest information on pathophysiology, diagnosis and management of important diseases of renal parenchyma. The information is presented in a very user friendly and accessible manner while the treatment algorithms enable the reader to quickly access expert advice on arriving at the most appropriate treatment regimen. The book discusses the renal involvement in various systemic diseases including diabetes and autoimmune diseases. Diabetic nephropathy is fast becoming the commonest cause of end stage renal disease all over the globe and is discussed in this book. The editors believe that this book will be a valuable addition to the reader's library.

\title{
How to reference
}

In order to correctly reference this scholarly work, feel free to copy and paste the following:

Vlad Alexandrescu (2012). Is Limb Loss Always Inevitable for Critical Neuro-Ischemic Foot Wounds in Diabetic Patients with End Stage Renal Disease and Unfit for Vascular Reconstructions?, Diseases of Renal Parenchyma, Prof. Manisha Sahay (Ed.), ISBN: 978-953-51-0245-8, InTech, Available from: http://www.intechopen.com/books/diseases-of-renal-parenchyma/is-limb-loss-always-inevitable-for-criticalneuro-ischemic-foot-wounds-in-diabetic-end-stage-renal-d

\section{INTECH}

open science | open minds

\section{InTech Europe}

University Campus STeP Ri

Slavka Krautzeka 83/A

51000 Rijeka, Croatia

Phone: +385 (51) 770447

Fax: +385 (51) 686166

www.intechopen.com

\section{InTech China}

Unit 405, Office Block, Hotel Equatorial Shanghai

No.65, Yan An Road (West), Shanghai, 200040, China 中国上海市延安西路65号上海国际贵都大饭店办公楼 405 单元

Phone: +86-21-62489820

Fax: $+86-21-62489821$ 
(C) 2012 The Author(s). Licensee IntechOpen. This is an open access article distributed under the terms of the Creative Commons Attribution 3.0 License, which permits unrestricted use, distribution, and reproduction in any medium, provided the original work is properly cited. 